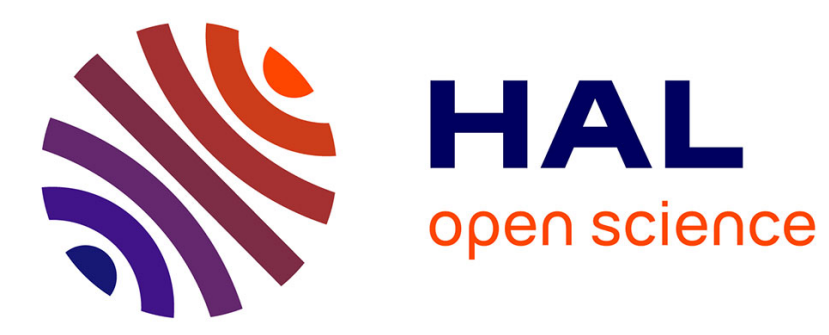

\title{
POINT DEFECT PARAMETERS FOR CALCIUM FLUORIDE FROM IONIC CONDUCTIVITY MEASUREMENTS AT LOW TEMPERATURES
}

\author{
P. Jacobs, S. Ong
}

\section{- To cite this version:}

P. Jacobs, S. Ong. POINT DEFECT PARAMETERS FOR CALCIUM FLUORIDE FROM IONIC CONDUCTIVITY MEASUREMENTS AT LOW TEMPERATURES. Journal de Physique Colloques, 1976, 37 (C7), pp.C7-331-C7-336. 10.1051/jphyscol:1976777 . jpa-00216937

\section{HAL Id: jpa-00216937 https://hal.science/jpa-00216937}

Submitted on 1 Jan 1976

HAL is a multi-disciplinary open access archive for the deposit and dissemination of scientific research documents, whether they are published or not. The documents may come from teaching and research institutions in France or abroad, or from public or private research centers.
L'archive ouverte pluridisciplinaire HAL, est destinée au dépôt et à la diffusion de documents scientifiques de niveau recherche, publiés ou non, émanant des établissements d'enseignement et de recherche français ou étrangers, des laboratoires publics ou privés. 


\title{
POINT DEFECT PARAMETERS FOR CALCIUM FLUORIDE FROM IONIC CONDUCTIVITY MEASUREMENTS AT LOW TEMPERATURES
}

\author{
P. W. M. JACOBS $\left({ }^{1}\right)$ and S. H. ONG \\ Department of Chemistry, University of Western Ontario, London, \\ Ontario N6A 5B7, Canada
}

\begin{abstract}
Résumé. - La conductivité des cristaux, purs et dopés au sodium, a été mesurée à des températures allant jusqu'à $1125 \mathrm{~K}$, en évitant toute réaction chimique entre le fluorure de calcium et la vapeur d'eau résiduelle, ou l'oxygène. Les données ont été analysées à l'aide de techniques des moindres carrés non linéaires pour obtenir des valeurs numériques des paramètres gouvernant la formation et la migration des défauts. Ces résultats sont comparés avec des travaux expérimentaux et théoriques antérieurs, et montrent que la valeur probable de l'énergie de formation des défauts de Frenkel dans le sous-réseau d'anions est $2,7 \mathrm{eV}$ et que les énergies de migration des lacunes et des interstitiels anioniques se situent respectivement dans les intervalles $0,35-0,55 \mathrm{eV}$ et 0,78 $0,92 \mathrm{eV}$.
\end{abstract}

\begin{abstract}
The ionic conductivity of pure and sodium doped calcium fluoride crystals has been measured at temperatures up to $1125 \mathrm{~K}$, avoiding chemical reaction of the calcium fluoride with residual water vapour or oxygen. The data have been analyzed using non-linear least squares techniques to yield numerical values of the parameters governing the formation and migration of defects. These results are compared with previous experimental and theoretical work and show that the probable value of the formation energy of Frenkel defects on the anion sub-lattice is $2.7 \mathrm{eV}$ and that the migration energies of anion vacancies and interstitials lie in the ranges 0.35 $0.55 \mathrm{eV}$ and $0.78-0.92 \mathrm{eV}$, respectively.
\end{abstract}

1. Introduction. - There have been several previous investigations of the ionic conductivity of calcium fluoride and yet a considerable measure of disagreement prevails concerning the numerical values of point defect parameters derived from these studies. There are similar variations in the results of theoretical calculations of point defect energies. These are illustrated in table I. Despite the variations recorded in the table it is clear that Frenkel defects in the anion sublattice must be the dominant type of intrinsic defect in $\mathrm{CaF}_{2}$, since ${ }_{2}^{1} u_{\mathrm{Fa}}<\frac{1}{3} u_{\mathrm{S}}<{ }_{2}^{1} u_{\mathrm{Fc}}$. Experimentally derived values of defect parameters for $\mathrm{CaF}_{2}$ [6-18] illustrate a far from satisfactory state of knowledge about the defect properties of $\mathrm{CaF}_{2}$. In none of these previous investigations has a thorough computerassisted data analysis been performed. Our objective was to perform such an analysis on conductivity data gathered over as wide a temperature range as possible. In fact we failed to obtain reliable data at high temperatures because of the well-known reactivity of $\mathrm{CaF}_{2}[6,19,20]$. Fortunately, the range of temperature that was covered and the density of data did permit a detailed analysis to be attempted.

(i) Member of Centre for Interdisciplinary Studies in Chemical Physics, University of Western Ontario.
2. Experimental. - Single crystals of pure $\mathrm{CaF}_{2}$ were obtained from the Harshaw Chemical Company. Although no analyses were carried out on these crystals one may infer from results published by others that the main impurities are likely to be, in p. p. m. : $\mathrm{Al}^{3+} 15$, $\mathrm{Si}^{3+} 5, \mathrm{Y}^{3+} 10, \mathrm{O}^{2-} 40$, together with detectable amounts of $\mathrm{Cl}^{-}, \mathrm{Sr}^{2+}, \mathrm{Mg}^{2+}[10,21]$. The conductivity cell was similar in principle to that used previously $[22,23]$ in studies on alkali halides but modified for higher temperatures. The data were analyzed as for alkalihalides [22] using the models described in the next section.

3. Defect models. - Even nominally pure crystals contain residual impurities that affect the conductivity at low temperatures. At first it was assumed that $\mathrm{NaF}$ would be a likely impurity in $\mathrm{CaF}_{2}$ but this assumption did not lead to any consistent kind of analysis of the data. We were therefore led to assume that Harshaw $\mathrm{CaF}_{2}$ contains a small amount of trivalent cation impurity and this hypothesis did lead to a consistent analysis. Moreover, there is experimental evidence for the existence of $\mathrm{M}^{3+}$ impurity in the chemical analyses referred to above, in the ionic thermoconductivity experiments of Podgoršak and Moran [24] and in the dielectric measurements of Andeen and Fontanella [25] 


\section{TABLE I}

Calculated values, in $\mathrm{eV}$, of point defect energies for calcium fluoride

$\begin{array}{ccccc}\begin{array}{c}\text { Franklin } \\ {[1]}\end{array} & \begin{array}{c}\text { Tharmalingam } \\ {[2]}\end{array} & \begin{array}{c}\text { Chakravorty } \\ {[3]}\end{array} & \begin{array}{c}\text { Catlow and } \\ \text { Norgett [4] }\end{array} & \begin{array}{c}\text { Keeton an } \\ \text { Wilson [5] }\end{array} \\ 5.8 & 4.3 & & - & \\ & & & 7.0-8.6 & \\ 2.7 & 2.8 & & 2.6-2.7 & 2.05 \\ 7.1 & 6.0 & & 8.5-9.2 & \\ & & & & \\ & & 0.64 & 0.15-0.20 & 0.4 \\ & & 1.56 & 0.69-0.72 & 1.5\end{array}$

on Harshaw $\mathrm{CaF}_{2}$. Experiments were also performed on $\mathrm{CaF}_{2}$ doped with NaF. Two models will therefore be examined (i) $\mathrm{M}^{+}$doped crystals and (ii) $\mathrm{M}^{3+}$ doped crystals.

3.1 $\mathrm{M}^{+}$DOPED CRYSTALS. - We shall assume that the $\mathrm{M}^{+}$ions are incorporated substitutionally on normal cation sites with charge compensation occurring by the incorporation of an equal number of anion vacancies. Franklin's [26] calculations do not furnish a clear guide on the mechanism by which $\mathrm{Na}^{+}$are incorporated in the $\mathrm{CaF}_{2}$ crystal for although the combinations $\mathrm{Na}_{\mathrm{i}}^{+}, \mathrm{F}_{\mathrm{i}}^{-}(\mathrm{i}=$ interstitial $)$ and $2 \mathrm{Na}_{\mathrm{s}}^{+}$, $\mathrm{Ca}_{\mathrm{i}}^{2+}$ ( $\mathrm{s}=$ substitutional) can be eliminated the calculated energies of solution of $\mathrm{NaF}$ with the formation of $\mathrm{Na}_{\mathrm{s}}^{+} \mathrm{F}_{\mathrm{v}}^{-}$( $\mathrm{v}=$ vacancy) and $\mathrm{Na}_{\mathrm{s}}^{+} \mathrm{Na}_{\mathrm{i}}^{+}$are $1.5 \mathrm{eV}$ and $1.3 \mathrm{eV}$ respectively. Thus we might expect $\mathrm{Na}^{+}$ ions to be present both substitutionally and interstitially. However, the matter may be decided by the symmetry of the defect. $\mathrm{Na}_{\mathrm{s}}^{+} \mathrm{Na}_{\mathrm{i}}^{+}$complexes have tetragonal symmetry and would therefore couple with a stress along $\langle 100\rangle$ or $\langle 110\rangle$, but not $\langle 111\rangle$, whereas $\mathrm{Na}_{\mathrm{s}}^{+} \mathrm{F}_{\mathrm{v}}^{-}$complexes have trigonal symmetry and therefore couple with a stress along $<111\rangle$ or $\langle 110\rangle$, but not $\langle 100\rangle$. As pointed out by Lidiard [27] the absence of a $\sigma<100>$ relaxation in the anelastic measurements of Johnson et al. [28] is clear evidence for charge compensation of the substitutional $\mathrm{Na}^{+}$ions by $\mathrm{F}^{-}$vacancies. In addition the formation of intrinsic Frenkel defects on the anion sublattice must be considered. By the usual statistical thermodynamical arguments one derives the equilibrium conditions

$$
\begin{aligned}
\frac{c_{\mathrm{k}_{1}}}{\left(c_{1}^{0}-c_{\mathrm{k}_{1}}\right) c_{\mathrm{v}}} & =z_{1} \exp \left(-g_{\mathrm{a}_{1}} / k T\right) \equiv K_{\mathrm{a}_{1}}^{\prime} \\
c_{\mathrm{i}} c_{\mathrm{v}} & =\exp \left(-g_{\mathrm{F}} / k T\right) \equiv K_{\mathrm{F}}^{\prime}
\end{aligned}
$$

where $g_{\mathrm{F}}$ is the non-configurational change in the Gibbs function on forming a Frenkel defect pair on the anion sub-lattice and $g_{a_{1}}$ is the non-configurational change in the Gibbs function on forming a $\mathrm{M}_{\mathrm{s}}^{+} \mathrm{F}_{\mathrm{v}}^{-}$complex from isolated substitutional $\mathrm{M}^{+}$ions and $\mathrm{F}^{-}$vacancies. $c_{\mathrm{k}_{1}}$ is the site fraction of $\mathrm{M}^{+}$on the cation sublattice that are in complexes; $c_{v}$ is the site fraction of anion vacancies $; c_{1}$ is the site fraction of unassociated $\mathrm{M}^{+}$on the cation sub-lattice; $c_{1}^{\circ}$ is the site fraction of total $\mathrm{M}^{+}$ impurity on the cation sub-lattice $=c_{1}+c_{\mathrm{k}_{1}}$; and $z_{1}$ is the number of anion sites that are nn to a cation site $=8$ in the fluorite lattice. Note the use of site fractions in (2). If mole fractions $x_{\mathrm{v}}$ are used a factor 2 appears on the RS of (2) since $x_{\mathrm{v}}=2 c_{v}$. Defect interactions have been neglected in deriving (1) and (2) but may be accounted for by replacing each $c_{\mathrm{r}}$ by $\gamma_{\mathrm{r}} c_{\mathrm{r}}$ where $\gamma_{r}$ is the activity coefficient of species $r$.

Conservation of change and lattice sites yields

$$
c_{1}+c_{i}=2 c_{\mathrm{v}}
$$

and conservation of impurity is expressed by

$$
c_{1}^{0}=c_{1}+c_{\mathrm{k}_{1}} .
$$

These constraints together with the two equilibrium conditions incorporating activity coefficients $\left({ }^{1}\right)$

$$
\begin{aligned}
c_{\mathrm{i}} c_{\mathrm{v}} & =K_{\mathrm{F}}^{\prime} / \gamma_{\mathrm{i}} \gamma_{\mathrm{v}} \equiv K_{\mathrm{F}} \\
c_{\mathrm{k}_{1}} / c_{1} c_{\mathrm{v}} & =K_{\mathrm{a}_{1}}^{\prime} \gamma_{1} \gamma_{\mathrm{v}} \equiv K_{\mathrm{a}_{1}}
\end{aligned}
$$

provide four equations using which $c_{\mathrm{k}_{1}}, c_{1}$, and $c_{\mathrm{i}}$ may be eliminated in favour of $c_{v}$. The resulting cubic equation

$$
2 c_{\mathrm{v}}^{3}+2 c_{\mathrm{v}}^{2} K_{\mathrm{a}_{1}}^{-1}-c_{\mathrm{v}}\left(c_{1}^{0} K_{\mathrm{a}_{1}}^{-1}+K_{\mathrm{F}}\right)-K_{\mathrm{F}} K_{\mathrm{a}_{1}}^{-1}=0
$$

may be solved numerically for $c_{y}$, if values of $c_{1}^{0}, K_{\mathbf{F}}$ and $K_{\mathrm{a}_{1}}$ are specified. The conductivity $\sigma$ may then be calculated from

$$
\sigma=\bar{N} e\left(c_{\mathrm{i}} u_{\mathrm{i}}+2 c_{\mathrm{v}} u_{\mathrm{v}}\right)
$$

where $\bar{N}$ is the number of cation sites per unit volume ( $=\frac{1}{2} a^{3}$ where $a$ is the $F^{-} \mathrm{F}^{-}$nn distance), $u_{\mathrm{v}}$ is the mobility of species $\mathrm{r}$ and $e$ is the charge on the proton.

(1) Since we anticipate using the Debye-Hückel approximation for $\gamma_{\mathbf{r}}, \gamma_{\mathrm{k}}$ is set equal to unity. 
By treating this as a non-linear least squares problem, the nine parameters $c_{1}^{0}, h_{\mathrm{F}}, s_{\mathrm{F}}, h_{\mathrm{a}_{1}}, s_{\mathrm{a}_{1}}, \Delta h_{\mathrm{i}}, \Delta s_{\mathrm{i}}, \Delta h_{\mathrm{v}}, \Delta s_{\mathrm{v}}$ on which the conductivity depends, may be evaluated $[29,30] . h_{\mathrm{r}}, s_{\mathrm{r}}$ denote the enthalpy and entropy corresponding to $g_{\mathrm{r}}$ and $\Delta$ indicates a mobility parameter, as in :

$$
u_{\mathrm{r}}=g_{0}\left(e a^{2} v / k T\right) S_{\mathrm{r}} \xi_{\mathrm{r}} \exp \left(-\Delta g_{\mathrm{r}} / k T\right)
$$

$S_{\mathrm{r}}$ is a symmetry number equal to 3 for both vacancy jumps and non-collinear interstitially (inc) jumps and $a \xi_{\mathrm{r}}$ is the component of the jump distance resolved along the direction of the field, $\langle 111\rangle$. For vacancy jumps $\xi_{\mathrm{v}}=1 / \sqrt{3}$ and for inc jumps $\xi_{\mathrm{i}}=2 / \sqrt{3} \cdot g_{0}$ is the Onsager-Pitts mobility factor [31] which corrects for the effect of the Debye-Hückel ion atmosphere on the mobile defect. The effective vibrational frequency $v$ in (9) was assumed to be equal to the frequency of the longitudinal optical mode $\left(1.4 \times 10^{12} \mathrm{~s}^{-1}\right)$ given by Elcombe and Pryor [32]. In calculating the conductivity the temperature-dependence of both the lattice parameter $a$ and the permittivity $\varepsilon$ were allowed for using the following expressions derived by fitting the results of Sirdeshmukh and Deshpande [33] and Rao and Smakula [34] respectively:

$$
\begin{aligned}
a & =\left(2.719+4.94948 \times 10^{-5} t\right) \times 10^{-10} \mathrm{~m} \\
\varepsilon / \varepsilon_{0} & =6.3677+1.9787 \times 10^{-3} t- \\
& -4.10426 \times 10^{-6} t^{2}+5.74074 \times 10^{9} t^{3}
\end{aligned}
$$

where $t=T-273.15 \mathrm{~K}$.

3.2 $\mathrm{M}^{3+}$ DOPED CRYSTALS. - The density measurements of Short and Roy [35] show unequivocally that charge compensation in $\mathrm{CaF}_{2}: \mathrm{YF}_{3}$ occurs by the formation of $\mathrm{F}^{-}$interstitials. Proceeding as in $\S 3.1$ one derives the cubic equation

$2 c_{\mathrm{v}}^{3}+c_{\mathrm{v}}^{2}\left(c_{2}^{0}+2 K_{\mathrm{F}} K_{\mathrm{a}_{2}}\right)-c_{\mathrm{v}} K_{\mathrm{F}}-K_{\mathrm{a}_{2}} K_{F}^{2}=0$

which is again solved iteratively until the vales of nine parameters $c_{2}^{0}, h_{\mathrm{F}}, s_{\mathrm{F}}, h_{\mathrm{a}_{2}}, s_{\mathrm{a}_{2}}, \Delta h_{\mathrm{i}}, \Delta s_{\mathrm{i}}, \Delta h_{\mathrm{v}}, \Delta s_{\mathrm{v}}$ minimize the sum of the squares of the deviations between calculated and experimental conductivities.

$$
K_{\mathrm{a}_{2}}\left(\gamma_{\mathrm{M}^{3}}+\gamma_{\mathrm{i}}\right)=z_{2} \exp \left(-g_{\mathrm{a}_{2}} / k T\right)
$$

is the equilibrium constant for the formation of $\mathrm{M}_{\mathrm{S}}^{3+} \mathrm{F}_{\mathrm{i}}^{-}$complexes from isolated substitutional $\mathrm{M}^{3+}$ ions and fluorine ion interstitials. $z_{2}$ is the number of interstitial sites that are $\mathrm{nn}$ to an $\mathrm{M}^{3+}$ site $=6$.

4. Results. - A plot of $\log \sigma T$ against $10^{3} K / T$ for a nominally pure Harshaw crystal is shown in figure 1 . This has the usual form of a conductivity plot with the curvature in the extrinsic region due to association clearly visible. The large number of experimental points (140) is necessary for least squares analysis. Figure 2 shows the deviations between experimental and calculated best-fit conductivities in the form of a plot of $\log (\sigma T)_{\mathrm{e}}-\log (\sigma T)_{\mathrm{c}}$ versus $10^{3} K / T$. (Subscript denotes experimental values and subscript $c$ denotes

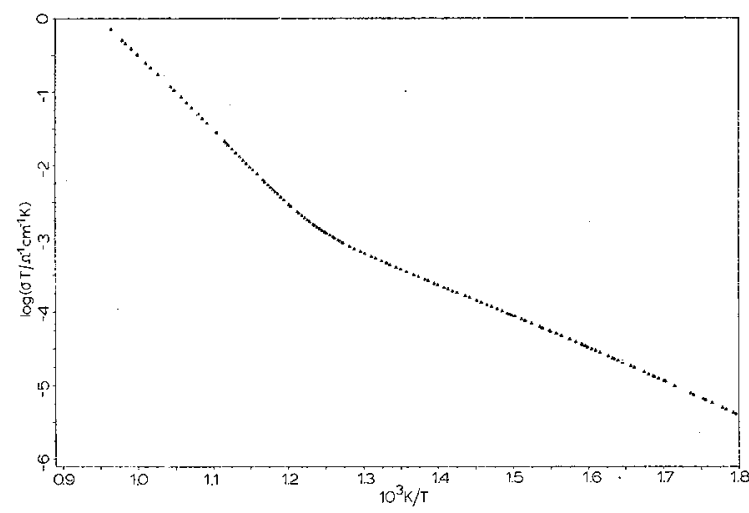

FIG. 1. - Ionic conductivity $\sigma$ of nominally pure calcium fluoride (crystal 43) in the form of a plot of $\log \sigma T$ against $10^{3} / T$.

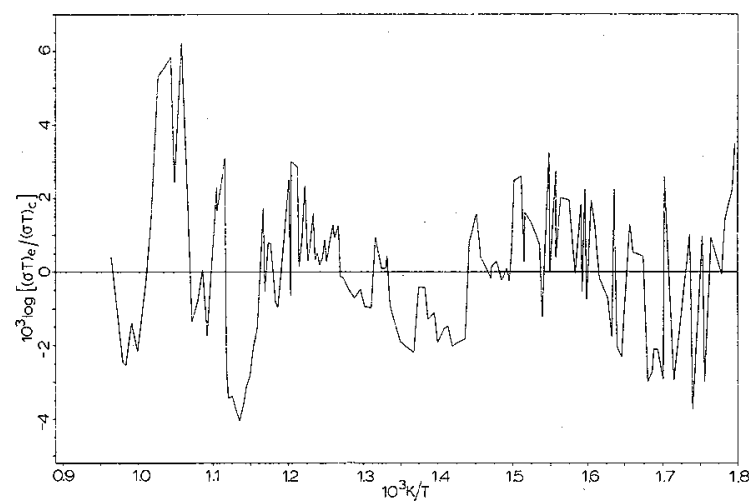

FIG. 2. - The difference between experimental (e) and calculated (c) values of $\log (\sigma T)$ for crystals 43 , plotted as a function of $10^{3} \mathrm{~K} / \mathrm{T}$. The deviations show a reasonable approximation to random behaviour without systematic trends.

calculated values.) Nearly all the deviations lie well within $1 \%$ of $\sigma T$ which corresponds to horizontal lines at \pm 0.0043 . The deviations approximate random behaviour reasonably well, suggesting the adequacy of the model and convergence of the least squares calculation. Parameter values and standard deviations are given in table II both for this run and for a second run on another Harshaw crystal illustrated in figures 3 and 4 . The calculated impurity concentrations are about $0.3 \times 10^{-6}$ site or mole fraction of $\mathrm{M}^{3+}$ ion. The conductivity of a $\mathrm{Na}^{+}$doped crystal is shown in figure 5 and the deviations between $\log (\sigma T)_{\mathrm{e}}$ and $\log (\sigma T)_{\mathrm{c}}$ for this 164-point run are depicted in figure 6 .

The analysis of the data was carried out as described in $\S 3$ but with the following modification made necessary by the restricted temperature range over which data could be taken. The pure crystal data were analyzed first giving rough values for all parameters. The results for the $\mathrm{Na}^{+}$doped crystal were then analyzed holding the Frenkel defect formation parameters $h_{\mathrm{F}}$ and $s_{\mathrm{F}}$ constant. The pure crystal data were then re-analyzed holding $\Delta h_{\mathrm{v}}$ constant and the cycle repeated until adequate convergence was obtained with consistent parameter values. However, the best fit to the 


\section{TABLE II}

Defect parameters for calcium fluoride derived from a least squares analysis of conductivity data $L=$ number of points and s. $d .=$ standard deviation. For the pure crystals $j=2 i . e . h_{\mathrm{a}}, s_{\mathrm{a}}$ and $c^{0}$ refer to an unidentified $\mathrm{M}^{3+}$ impurity; for $\mathrm{CaF}_{2}: \mathrm{Na}^{+} j=1$ and they refer to $\mathrm{Na}^{+}$. An underlined value means that this parameter was held constant during the final iterations

Crystal

\begin{tabular}{|c|c|c|c|c|c|c|c|c|c|c|c|}
\hline pure $j=2$ & $h_{\mathrm{F}} / \mathrm{eV}$ & $s_{\mathrm{F}} / k$ & $\Delta h_{\mathrm{i}} / \mathrm{eV}$ & $\Delta s_{i} / k$ & $\Delta h_{\mathrm{v}} / \mathrm{eV}$ & $\Delta s_{\mathrm{v}} / k$ & $-h_{\mathrm{aj}} / \mathrm{eV}$ & $-s_{\mathrm{a}, \mathrm{j}} / k$ & $c_{\mathbf{j}}^{0} \times 10^{6}$ & $L$ & s.d. $\times 10^{3}$ \\
\hline$\overline{43}$ & $\overline{272}$ & $\overline{542}$ & $\overline{70}$ & $\overline{560}$ & - & $\overline{103}$ & $\overline{0.63}$ & $\overline{0} 01$ & $\overline{285}$ & $\overline{140}$ & $\overline{109}$ \\
\hline 44 & 2.71 & $\begin{array}{l}5.42 \\
5.64\end{array}$ & 0.79 & $\begin{array}{l}5.00 \\
5.37\end{array}$ & $\frac{0.47}{0.47}$ & $\begin{array}{l}1.93 \\
1.72\end{array}$ & $\begin{array}{l}0.03 \\
0.67\end{array}$ & -0.01 & 0.351 & 135 & 1.75 \\
\hline $\begin{array}{c}\mathrm{Na}^{+} \text {doped } \\
j=2\end{array}$ & & & & & & & & & & & \\
\hline 40 & 2.71 & 4.08 & 0.77 & 7.27 & 0.38 & 1.13 & 0.71 & 1.54 & 7.15 & 166 & 2.21 \\
\hline
\end{tabular}

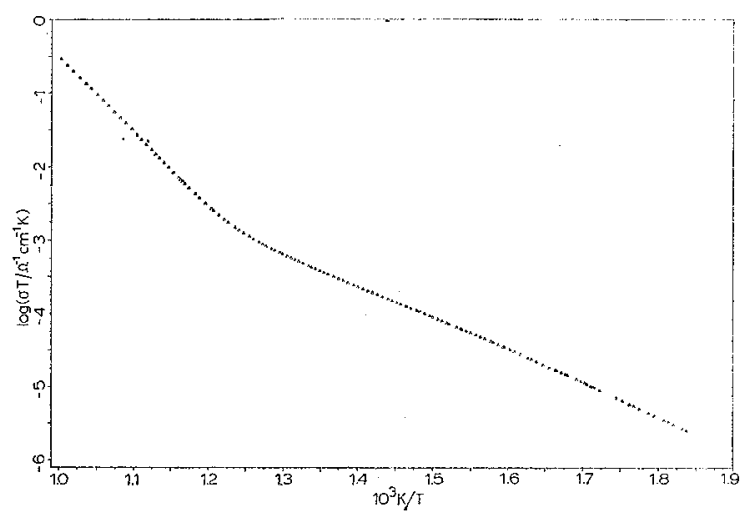

FIG. 3. - Ionic conductivity $\sigma$ of nominally pure calcium fluoride (crystal 44).

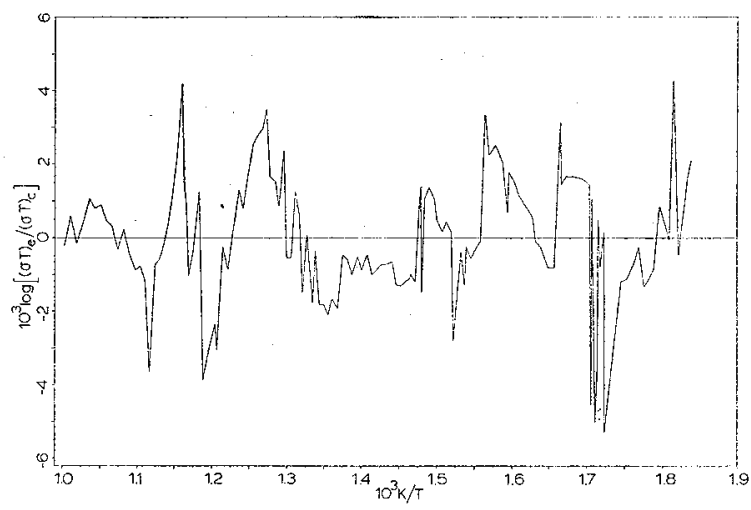

FIG. 4. - Deviations between experimental and calculated values of $\log (\sigma T)$ for crystal 44.

conductivity of the pure crystals was obtained if the constant value of $\Delta h_{\mathrm{v}}$ was made slightly higher than the converged value for the $\mathrm{Na}^{+}$doped crystal (Table II). There is thus a slight inconsistency between the pure and doped crystal data: we hope to resolve this by further measurements on $\mathrm{CaF}_{2}$ crystals doped with $\mathrm{M}^{+}$ ions.

5. Discussion. - The experimental values of the thermodynamic parameters governing the formation,

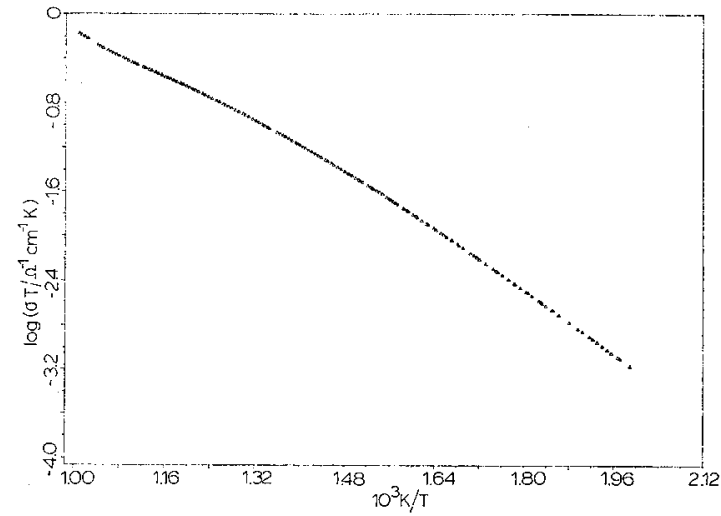

FIG. 5. - Ionic conductivity of calcium fluoride doped with sodium fluoride (crystal 40).

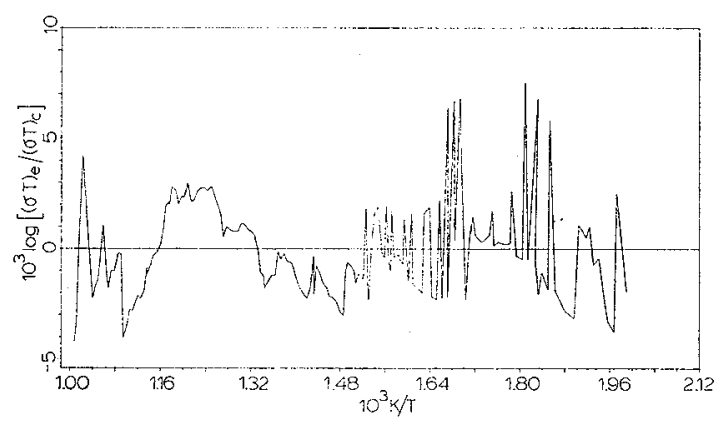

FIG. 6. - Deviations between experimental and calculated values of $\log (\sigma T)$ for crystal 40.

migration and interaction of defects in $\mathrm{CaF}_{2}$ which are given in table II may be compared with the theoretically calculated values in table $I$ and with the experimental results of other workers [6-18]. Both theory $\left({ }^{2}\right)[4]$ and experiment $([11,15,17]$ and

(2) The theoretically calculated values are internal energies at $0 \mathrm{~K}$ while the experimental values are mean enthalpies over the temperature range covered by the measurements. However, they may be compared directly since the $p v$ terms in $h_{\mathrm{r}}=u_{\mathbf{r}}+p v_{\mathrm{r}}$ are liable to be negligibly small at ordinary pressures. 
Table II) yield values for the formation energy of a Frenkel defect pair on the anion sub-lattice in the range $2.60-2.74 \mathrm{eV}$ and a number close to $2.70 \mathrm{eV}$ would seem to be the most probable value. There is far less agreement about the corresponding entropy, the experimental values varying between $13.5 \mathrm{k}$ [6] and $5.5 \mathrm{k}$ (Table II).

The experimental value we find for $\Delta h_{\mathrm{i}}$ shows remarkable consistency between the three runs. The mean value of $0.78 \mathrm{eV}$ is significantly lower than the other experimental values given in table II. Probably this is due to the lower value of $\mathrm{M}^{3+}$ impurity in our crystal so that the simple association model is almost certainly valid whereas there may be other defect complexes present at higher concentrations. Our value is in rather good agreement with Catlow and Norgett's [4] value of $0.72 \mathrm{eV}$ for the nc interstitialcy jump calculated from their potential 3 . Their originally calculated value of $0.15 \mathrm{eV}$ for an anion vacancy jump seems to be much lower than any of the experimental values recorded, but a recently revised value of $0.35 \mathrm{eV}$ from a new potential, is very close to our experimental value of $0.38 \mathrm{eV}$ from a $\mathrm{CaF}_{2}: \mathrm{Na}^{+}$run. However, the pure crystal data could not be fitted with such a low value for $\Delta h_{\mathrm{v}}$ which had to be raised to $0.47 \mathrm{eV}$. This value is closer to other conductivity values of 0.51 $0.55 \mathrm{eV}[11,15,17]$. We hope to resolve this anomaly by further experiments on $\mathrm{M}^{+}$-doped $\mathrm{CaF}_{2}$. Nevertheless it now seems quite certain that $\Delta h_{\mathrm{v}}$ is in the range $0.35-0.55 \mathrm{eV}$ and $\Delta h_{\mathrm{i}}$ in the range $0.78-0.92 \mathrm{eV}$, Catlow, Norgett and Ross' [36] new value for the inc jump being $0.91 \mathrm{eV}$. As for alkali halides [22] the entropy changes for interstitial jumps $(\sim 5-7 \mathrm{k})$ seem to be higher than for vacancy jumps (1-2 k) (Table II $[15,16])$.

There is not much agreement at present over the value of the association energy $-\Delta h_{\mathrm{a}_{1}}$, our value of $0.65 \mathrm{eV}$ lying between other experimental values of $1.03 \mathrm{eV}$ [15] and $0.44 \mathrm{eV} \mathrm{[17].} \mathrm{In} \mathrm{contrast} \mathrm{our} \mathrm{value}$ for $-\Delta h_{\mathrm{a}_{1}}$ agrees with that of $0.68 \mathrm{eV}$ from Bollmann and Reimann [16]. Association entropies are not determined very accurately by our method of data analysis because of their relatively small affect on the conductivity.

Acknowledgment. - We are grateful for the support of this research by the National Research Council of Canada.

\section{References}

[1] Frankuin, A. D., J. Phys. \& Chem. Solids 29 (1968) 823.

[2] Tharmalingam, K., Phil. Mag. 23 (1971) 199.

[3] Chakravorty, D., J. Phys. \& Chem. Solids 32 (1971) 1091.

[4] Catlow, C. R. A. and Norgett, M. J., J, Phys. C 6 (1973) 1325.

[5] Keeton, S. C. and Wilson, W. D., Phys. Rev. B 7 (1973) 834.

[6] URe, R. W., J. Chem. Phys. 26 (1957) 1363.

[7] FIeLder, W. L., N. A. S. A. Technical Report No. TND3816 (1967).

[8] Barsis, E. and Taylor, A., J. Chem. Phys. 45 (1966) 1154.

[9] Lysiak, R. J. and Mahendroo, P. P., J. Chem. Phys. 44 (1966) 4025

[10] Keig, G. A. and Coble, R. L., J. Appl. Phys. 39 (1968) 6090.

[11] Bóllmann, W., Görlich, P., Hauk, W. and Mothes, H., Phys. Status Solidi 2 (1970) 157.

[12] MATZKe, H., J. Mat. Sci. 5 (1970) 831.

[13] Twidell, J. W., J. Phys. \& Chem. Solids 31 (1970) 299.

[14] Popov, V. V., Sov. Phys. Solid State 11 (1970) 1594.

[15] Bollmann, W. and Henniger, H., Phys. Status Solidi (a) 11 (1972) 367.

[16] Bollmann, W. and Reimann, R., Phys. Status Solidi (a) 16 (1973) 187.

[17] MogileVskir, B. M., Romanov, V. N., Reiterov, V. M., Trofimova, L. M. and ChudnovskiI, A. F., Sov. Phys. Solid State 15 (1973) 728.

[18] Van Steenwinkel, R., Z. Naturforsch. 29a (1974) 278.
[19] Stockbargeter, D. C., J. Opt. Soc. Amer. 39 (1949) 731.

[20] Bontinck, W., Physica 24 (1958) 650.

[21] Evans, A. G. and Pratt, P. L., Phil. Mag. 20 (1969) 1213.

[22] Jacoss, P. W. M. and Pantelis, P., Phys. Rev. B 4 (1971) 3757.

[23] Alunatt, A. R. and JAcoBs, P. W. M., Trans. Faraday Soc. 58 (1962) 116.

[24] Podgoršak, E. B. and Moran, P. R., Phys. Rev. B 8 (1973) 3405.

[25] Andeen, C. and Fontandlla, J., private communication. [26] Frankitn, A. D., J. Amer. Ceram. Soc. 50 (1967) 648.

[27] LidiARD, A. B., in Crystals with the Fluorite Structure, ed. W. Hayes (Clarendon Press, Oxford) 1974.

[28] Johnson, H. B., Tolar, N. J., Mrller, G. R. and CutLER, I. B., J. Phys. \& Chem. Solids 30 (1969) 31.

[29] Beaumont, J. H. and Jacobs, P. W. M., J. Chem. Phys. 45 (1966) 1496.

[30] Brown, N. and JAcoBs, P. W. M., J. Physique Colloq. 34 (1973) C 9-437.

[31] PrtTs, E., Proc. R. Soc. London A 217 (1953) 48.

[32] Elcombe, M. M. and Pryor, A. W., J. Phys. C 3 (1970) 492.

[33] Strdeshmukh, D. B. and Deshpande, V. T., Ind. J. Pure and Appl. Phys. 2 (1964) 405.

[34] Rao, K. V. and Smakula, A., J. Appl. Phys. 37 (1965) 319.

[35] Short, J. and Rox, R., J. Phys. Chem. 67 (1963) 1860.

[36] Catlow, C. R. A., Norgett, M. J. and Ross, T. A., AERE, Harwell Rept. TP673 (1976). 


\section{DISCUSSION}

K. V. REDDY. - The association factor initially decreases as the temperature increases and at higher temperature the association factor increases with increase of temperature. Any explanation ?

P. W. M. JACOBS. - Yes : as $T$ increases $p_{2}$ decreases at first due to the decreasing value of the association constant $K_{\mathrm{a}_{2}}$. However, at higher temperatures $p_{2}$ increases again because the increasing number of interstitials from the Frenkel defect equilibrium more than compensates for the effect of temperature on $K_{\mathrm{a}_{2}}$.

M. J. NorgetT. - Prof. Jacobs has mentioned two of our calculations and passed rightly over an earlier effort. I should perhaps explain why we feel inclined to return to the problem of defects in fluorides from time to time. First I would say that we can now do calculations that are effectively an exact consequence of the assumptions we make about the lattice model. The results change from time to time as we gain more experience in formulating improved lattice models. It was after than assumed that rather such models are adequate, and there are cases where such models have been successful, but we are finding increasingly that quite subtle changes in interatomic potential can have profound effects on the calculated defect energies.

P. W. M. JACOBS. - There now seems to be an encouraging degree of agreement between theory and experiment for calcium fluoride. It is perhaps worth commenting that my becoming aware of the later Harwell calculations was one factor that led me to the analysis of the $\mathrm{CaF}_{2}: \mathrm{Na}^{+}$data-data which I had been somewhat (as it turns out unjustifiably !) suspicious of up to that point. The moral here is $I$ think two-fold : conductivity data won't analyze properly without the correct- or nearly correct-model. And secondly theory can in this field, as in others, provide a useful lead in the analysis experimental of data. 